\title{
Lichen, moss and soil in resolving the occurrence of semi-volatile organic compounds on the southeastern Tibetan Plateau, China
}

\author{
Nali Zhu ${ }^{\text {a }}$, Karl-Werner Schramm ${ }^{\text {b,c }}$, Thanh Wang ${ }^{\text {a }}$, Bernhard Henkelmann ${ }^{\text {b }}$, Jianjie Fu ${ }^{\text {a }}$, Yan Gao ${ }^{\text {a }}$ \\ Yawei Wang a,b,*, Guibin Jiang ${ }^{\mathrm{a}}$ \\ a State Key Laboratory of Environmental Chemistry and Ecotoxicology, Research Center for Eco-Environmental Sciences, Chinese Academy of Sciences, Beijing 100085, China \\ ${ }^{\mathrm{b}}$ Helmholtz Zentrum München - German Research Center for Environmental Health, Molecular EXposomics (MEX), Ingolstädter Landstrasse 1, D-85764, Germany \\ ' TUM, Wissenschaftszentrum Weihenstephan für Ernährung, Landnutzung und Umwelt, Department für Biowissenschaften, Weihenstephaner Steig 23, 85350 Freising, Germany
}

\section{H I G H L I G H T S}

- DDTs, endosulfans, HCHs and hexachlorobenzene predominated in all the samples.

- High detection frequency of HBCDs was only observed in lichen samples.

- Lichen concentrations of OCPs and PCBs increased with elevation in Tibetan Plateau.

- Lichen is more suitable to reveal airborne SVOC contamination than moss.

- SVOCs with $\log K_{\mathrm{OA}}$ (8-11) and $\log K_{\mathrm{WA}}(2-4)$ had high mountain contamination potential.

\section{A R T I C L E I N F O}

\section{Article history:}

Received 15 November 2014

Received in revised form 6 March 2015

Accepted 6 March 2015

Available online 12 March 2015

Editor: Adrian Covaci

\section{Keywords:}

Semi-volatile organic compounds

Lichen

Moss

Soil

Tibetan Plateau

Air

\begin{abstract}
A B S T R A C T
This study investigated a wide range of semi-volatile organic compounds (SVOCs), including 28 persistent organochlorine pesticides (OCPs), 18 polychlorinated biphenyls (PCBs), 13 polybrominated diphenyl ethers (PBDEs), and 3 hexabromocyclododecane (HBCD) congeners in lichen, moss and soil collected from the southeastern Tibetan Plateau, China. This allows research provides insight into elevation gradient distributions and possible cold trapping effects of SVOCs in this high mountain area, and compares lichens and mosses as air passive samplers for indicating SVOC occurrences. DDTs, endosulfans, HCHs and hexachlorobenzene predominated in all of the samples. Source analysis indicted that there were fresh inputs of DDTs and HCHs in the sampling region. Lichens and mosses shared commonalities in revealing the profiles and levels of SVOCs based on their lipidcontent-normalized concentrations. The concentrations of 12 OCPs and 14 PCBs in lichens were significantly linearly correlated with altitudes, whereas the correlations for mosses and soil with altitudes were insignificant. Both a frequency distribution diagram and the Mountain Contamination Potential Model indicated that SVOCs with specific values of $\log K_{\mathrm{OA}}(8-11)$ and $\log K_{\mathrm{WA}}(2-4)$ had relative high mountain contamination potential on the Tibetan Plateau.
\end{abstract}

(c) 2015 Elsevier B.V. All rights reserved.

\section{Introduction}

Semi-volatile organic compounds (SVOCs) are distributed globally through long-range atmospheric transport (LRAT) and have been detected in pristine regions far away from polluted areas such as in high latitude or altitude regions with cold climates (Estellano et al., 2008; Wang et al., 2009). Accompanied by further insight into the adverse effects of SVOCs to humans and the ecosystem, the occurrence and behavior of SVOCs in pristine environments have become a growing concern

\footnotetext{
* Corresponding author at: State Key Laboratory of Environmental Chemistry and Ecotoxicology, Research Center for Eco-Environmental Sciences, Chinese Academy of Sciences, Beijing 100085, China.

E-mail address: ywwang@rcees.ac.cn (Y. Wang).
}

in recent decades. Considering that electrical power is unavailable and that the access to high latitude or altitude regions is difficult, passive air sampling media, especially of vegetation, have been widely used to investigate the concentrations, distribution patterns and transport mechanisms of SVOCs in those remote regions; their popularity is due to their unique advantages in terms of electrical power savings, sampling convenience, and integration of air contamination over time (Cabrerizo et al., 2012; Daly et al., 2007; Harner et al., 2004; Liu et al., 2010; Ockenden et al., 1998). Various types of vegetation have been used as natural sampling media to evaluate atmospheric pollution of SVOCs since the 1980s (Buckley, 1982; Eriksson et al., 1989). Lichens (Augusto et al., 2009; Blais et al., 1998; Cabrerizo et al., 2012; Schrlau et al., 2011; Yogui et al., 2011), mosses (Cabrerizo et al., 2012; Cipro et al., 2011; Wang et al., 2012; Yogui et al., 2011), tree bark (Salamova 
and Hites, 2010; Tarcau et al., 2013) and pine needles (Blais et al., 1998; Schrlau et al., 2011; Yang et al., 2008) are the most commonly used vegetation because of their high lipid content, large surface area and great seasonal availability. Lichens and mosses, due to lack of barrier structures and root-like structures, can directly absorb gas-phase, aerosol and particle-bound pollutants from the atmosphere (Kansri et al., 1990; Madl et al., 2010; Yogui et al., 2011) and integrate air contamination over time (Simonich and Hites, 1995). Some research has reported an accumulation difference among the various air samplers (Schrlau et al., 2011; Tarcau et al., 2013; Yang et al., 2013). Schrlau et al (2011) compared the accumulation difference of SVOCs in lichen and XADpassive sampler, and indicated that lichens could accumulate more SVOCs with octanol-air partition coefficients of $\log \mathrm{Koa}>10$, whereas XAD mainly accumulated gas-phase SVOCs.

The Tibetan Plateau is often called the roof of the world, with an average altitude at $4000 \mathrm{~m}$ above sea level. It is one of the coldest and most remote regions in the world. The sparse human population, minimal to nonexistent industrial activities and hardly any identified or reported local sources of SVOCs, except for some organic chlorinated pesticides (OCPs), this high mountain region is considered to be an ideal natural setting for researching environmental fate and long-range atmospheric transportation of SVOCs. Previous researches have indicated the existence of some SVOCs with topographic cold trapping effect (Liu et al., 2010; Wang et al., 2009; Yang et al., 2008) in the Tibetan Plateau.

The purpose of this study was to use lichen (Usnea longissima), mosses (Hypnaceae and Pottiaceae) and corresponding soil samples to comprehensively investigate the spatial distributions, contamination level, source and cold trapping effect of SVOCs on the southeastern Tibetan Plateau, to gain further insight into the main differences and similarities between lichens and mosses as passive samplers indicating the occurrence of SVOCs in the atmosphere. The target compounds included 28 organochlorine pesticides (OCPs), 18 polychlorinated biphenyls (PCBs), 13 polybrominated diphenyl ethers (PBDEs), and 3 hexabromocyclododecane (HBCD) isomers.

\section{Material and methods}

\subsection{Sampling}

A sampling area was chosen on the southeast of the Tibetan Plateau. Compared with other parts, the southeast region is characterized by mountain-valley topography, containing the densest pristine forests. The large moisture passage of the Yarlung Tsangpo Valley nearby provides a constant stream of moisture to this region. The climate there is dominated alternatively by an Indian monsoon in summer and westerly wind in winter, likely bringing SVOCs from potential sources nearby onto the Tibetan Plateau (Sheng et al., 2013; Wang et al., 2010; Zhu et al., 2014). In this study, a total of 140 samples (consisting of 45 lichen, 49 moss and 46 soil samples) were collected from 75 sampling sites at a range of $920 \mathrm{~km} \times 228 \mathrm{~km}$ on the southeast of the Tibetan Plateau (Fig. S1, Table S1) in late June 2010 and 2011. The moss and soil samples were nearly all collected at the same sites during the same field trip as paired samples; however, only 19 lichen samples were collected from the same sites as the moss and soil samples during the same field trip. Detailed information about the sampling can be found in Table S1 in the Supplementary content.

Because of the geographical restrictions and species distribution, two families of moss, i.e. Pottiaceae and Hypnaceae, were collected from the southeastern Tibetan Plateau. All of the collected lichen samples belong to $U$. longissima (Table S1). The composite lichen samples were taken from heights between 1.5 and $2.0 \mathrm{~m}$ above the ground from six different spots on the sampling tree. For the moss and surface soil $(0-5 \mathrm{~cm})$, each sample included a blend of six portions collected from six different segments within $30 \mathrm{~m}$ of the sampling sites. The samples were wrapped in aluminum foil, sealed in plastic bags, stored in insulation ice-boxes (polyester), and immediately taken back to the laboratory after sampling. After being rinsed with deionized water, the lichen and moss samples were lyophilized, ground, and then kept at $-20^{\circ} \mathrm{C}$ in sealed plastic bags until the sample treatment. The soil samples were also freeze-dried, screened, and kept at $-20^{\circ} \mathrm{C}$ in sealed plastic bags until sample treatment. Anhydrous sodium sulfate aliquot was included as a blank for this procedure.

\subsection{Sample preparation and instrumental analysis}

An isotope-dilution method was used to analyze the target compounds in this research. Two pretreatment methods, reported previously (Botaro et al., 2011; Wang et al., 2009; Zhu et al., 2012), were used to extract and concentrate OCPs and the three other types of organic pollutants (PBDEs, PCBs and HBCDs) from the samples. A detailed description of the pretreatment methods can be found in the Supplementary content.

Twenty-eight pesticides were identified with a GC-MS system composed of a gas chromatograph (Agilent 5890) and a mass spectrometer (Finnigan MAT 95). Thirteen PBDEs and eighteen PCB congeners were quantified using a HRGC-HRMS (Agilent 6890N/AutoSpec Ultima) system. Three HBCD isomers were analyzed with a HPLC-MS/MS system composed of high performance liquid chromatography (Waters 2695) and triple-quadrupole mass spectrometer (Waters Micromass). Detailed information about the instrument configuration, operational procedures and conditions for analyzing OCPs, PCBs and PBDEs, and HBCDs could be found in previous research (Feng et al., 2010; Wang et al., 2009; Zhu et al., 2014).

The total organic carbon (TOC) content of the soil samples was determined with a TOC Analyzer (OI Analytical, USA).

\subsection{Quality assurance/quality control}

A procedural blank was included and processed in parallel with each batch of 11 samples to check for interference and cross-contamination. The average recoveries of ${ }^{13} \mathrm{C}$-labeled internal standards for OCPs, PCBs, PBDE, and HBCDs in all of the lichen samples were $73 \pm 16 \%, 77 \pm 21 \%$, $62 \pm 9.0 \%$, and $83 \pm 16 \%$, respectively. Similarly, they were, respectively, $84 \pm 18 \%, 88 \pm 23 \%, 76 \pm 5.0 \%$, and $93 \pm 14 \%$ in mosses, and $65 \pm$ $12 \%, 78 \pm 9.0 \%, 68 \pm 13 \%$, and $82 \pm 12 \%$ in soil. The method detection limits (MDLs), defined as 3 times signal-to-noise ratio $(\mathrm{S} / \mathrm{N})$, for OCPs, PCBs, PBDEs and HBCDs were $0.57-17 \mathrm{pg} / \mathrm{g}, 0.10-0.62 \mathrm{pg} / \mathrm{g}, 0.21-$ $3.6 \mathrm{pg} / \mathrm{g}$, and $0.29-0.38 \mathrm{ng} / \mathrm{g}$ in the lichen samples, $1.7-42 \mathrm{pg} / \mathrm{g}$, $0.090-0.45 \mathrm{pg} / \mathrm{g}, 0.21-4.2 \mathrm{pg} / \mathrm{g}$, and $0.31-0.43 \mathrm{ng} / \mathrm{g}$ in the moss samples, and $0.16-4.6 \mathrm{pg} / \mathrm{g}, 0.19-0.83 \mathrm{pg} / \mathrm{g}, 0.10-1.3 \mathrm{ng} / \mathrm{g}$, and $0.29-0.37 \mathrm{ng} / \mathrm{g}$ in the soil samples, respectively. The quantification limits were defined as 10 times the $\mathrm{S} / \mathrm{N}$. The resulting data were adjusted using blank values in light of the following rules: the resulting value $(\mathrm{R})=$ the sample value - the average blank value $(X)$; if the $R$ was larger than 3 times the standard deviation of $\mathrm{X}$, the value of $\mathrm{R}$ was deemed valid and reported as a result, otherwise the $\mathrm{R}$ was reported as not detectable, and valued as zero to calculate the related medians and means. Statistical tests were performed using SPSS (Statistical Product and Service Solutions, V. 16.0, SPSS Inc., CHI, USA). Independent-sample T-tests were used to determine the significant difference between samples, with a significance level of 0.05 . Two-tailed Pearson's correlation tests were processed to determine the correlations among samples.

\section{Results and discussion}

\subsection{Concentrations and profiles of SVOCs in lichen, moss and soil samples}

Data summaries of the SVOC concentrations and detection frequencies in the three different matrices were shown in Tables S2, S3 and S4 in the Supplementary content. Independent-sample T-test indicated that there were no significant differences $(p>0.05)$ between the SVOC concentrations of the two families (Pottiaceae and Hypnaceae) of moss. 
Among all of the targeted compounds, the OCPs were the dominant pollutants and their concentrations were higher than those of the PCBs and PBDEs by one to two orders of magnitude, whereas the PBDEs had the lowest concentrations. As a type of emerging SVOC, the HBCDs were detected in $62 \%$ of the lichen samples and their concentrations were only slightly higher than those of the PBDEs. In general, the concentrations of the target SVOCs in the southeastern Tibetan region were at worldwide low levels and were comparable to observations from other background and remote areas (Bacci et al., 1986; Cabrerizo et al., 2012; Daly et al., 2007; Negoita et al., 2003; Park et al., 2010; Turgut et al., 2012; Yang et al., 2008; Yogui and Sericano, 2008).

As the predominant compounds in the samples, the average drymass-based concentration of $\sum_{28} \mathrm{OCP}$ in the soil, lichens and mosses was $1.2 \mathrm{ng} / \mathrm{g} \mathrm{dm}$ (ng/g dry mass) (ranging from 0.14 to $7.8 \mathrm{ng} / \mathrm{g} \mathrm{dm}$ ), $34 \mathrm{ng} / \mathrm{g} \mathrm{dm}$ (ranging from 9.5 to $79 \mathrm{ng} / \mathrm{g} \mathrm{dm}$ ), and $6.6 \mathrm{ng} / \mathrm{g} \mathrm{dm}$ (ranging from 0.54 to $34 \mathrm{ng} / \mathrm{g} \mathrm{dm}$ ), respectively. Therein, DDTs, endosulfans, $\mathrm{HCHs}$, and hexachlorobenzene predominated over the other OCPs, and accounted for $90 \%$ of the $\sum_{28} \mathrm{OCP}$ concentrations.

DDTs were the most abundant OCPs in each sample matrix, and accounted for $47 \%, 56 \%$ and $54 \%$ of the $\sum_{28} \mathrm{OCP}$ concentrations in lichens, mosses and soil, respectively. Correspondingly, the average concentrations of $\sum_{6}$ DDT in the three matrices were $16 \mathrm{ng} / \mathrm{g} \mathrm{dm}, 3.7 \mathrm{ng} / \mathrm{g}$ $\mathrm{dm}$ and $0.65 \mathrm{ng} / \mathrm{g} \mathrm{dm}$, respectively. The 4,4'-DDT, 2,4'-DDT, 4,4'-DDE, $4,4^{\prime}$-DDD, 2,4'-DDD and 2,4'-DDE accounted for $52 \%, 35 \%, 6.9 \%, 2.9 \%$, $2,6 \%$ and $1.2 \%$ of $\sum_{6}$ DDT in lichens, which was consistent with results reported for conifer needles in southeastern Tibetan (Yang et al., 2008). Similarly, 4,4'-DDT and 2,4'-DDT were the major components of DDTs in the moss samples, accounting for $50 \%$ and $31 \%$ of $\sum_{6}$ DDT, followed by $4,4^{\prime}$-DDE (16\%), 2,4'-DDE (1.8\%), 2,4'-DDD (1.1\%) and $4,4^{\prime}$-DDD $(0.8 \%)$. In contrast to the ones in lichens and mosses, the DDT profile in soil was as follows: $4,4^{\prime}$-DDT $(36 \%)>4,4^{\prime}$-DDE $(33 \%)>2,4^{\prime}$-DDT $(26 \%)>2,4^{\prime}$-DDE $(2.3 \%)>4,4^{\prime}$-DDD $(1.5 \%)=2,4^{\prime}-$ DDD (1.5\%), in which $4,4^{\prime}$-DDT and 4,4'-DDE were the predominant components. Faster aerobic degradation of $4,4^{\prime}$-DDT to $4,4^{\prime}$-DDE in the soil could be the main reason for this profile difference. Endosulfan was the second-most abundant OCP in both lichens and mosses, and the corresponding concentrations of $\sum_{2}$ endosulfan were $14 \mathrm{ng} / \mathrm{g} \mathrm{dm}$, $1.3 \mathrm{ng} / \mathrm{g} \mathrm{dm}$ and $0.067 \mathrm{ng} / \mathrm{g} \mathrm{dm}$ in lichens, mosses, and soil, respectively. Endosulfan has been reported as one of the most abundant OCPs in air from North-America (Shen et al., 2005). The mean ratios of endosulfan I/endosulfan II were 3.0 in lichens, 3.7 in mosses, and 4.1 in soil, which were higher than those in the technical mixture (2.0-2.3) (Estellano et al., 2008). Higher ratios in soils and plants were probably due to the conversion of endosulfan II to endosulfan I (Schmidt et al., 2001). The concentrations of $\sum_{5} \mathrm{HCH}$ in lichens, mosses and soil were $1.9 \mathrm{ng} / \mathrm{g}$ $\mathrm{dm}, 0.76 \mathrm{ng} / \mathrm{g} \mathrm{dm}$, and $0.14 \mathrm{ng} / \mathrm{g} \mathrm{dm}$, respectively, which were significantly lower than those of $\sum_{6}$ DDT. $\alpha-\mathrm{HCH}$ and $\gamma$ - $\mathrm{HCH}$ were the dominant congeners with respective proportion of $49 \%$ and $29 \%$ in lichen samples, followed by $\beta-\mathrm{HCH}(14 \%), \delta-\mathrm{HCH}(5.2 \%)$ and $\varepsilon-\mathrm{HCH}(2.4 \%)$. It was very close to the $\mathrm{HCH}$ profiles in the XAD-air-samplers sampled in the same region $(\alpha-\mathrm{HCH}(75 \%)>\gamma-\mathrm{HCH}(18 \%)>\beta-\mathrm{HCH}(6.5 \%)>\delta-$ $\mathrm{HCH}(0.87 \%)$ ) (Zhu et al., 2014). In contrast, the percentage of $\beta-\mathrm{HCH}$ was significantly higher than the $\gamma-\mathrm{HCH}$ in the $\mathrm{HCH}$ profiles of both the moss and soil samples as follows: $\beta-\mathrm{HCH}(41 \%)>\alpha-\mathrm{HCH}$ $(30 \%)>\varepsilon-\mathrm{HCH}(14 \%)>\gamma-\mathrm{HCH}(10 \%)>\delta-\mathrm{HCH}(4.5 \%)$ in mosses; and $\alpha-\mathrm{HCH}(44)>\beta-\mathrm{HCH}(40 \%)>\gamma-\mathrm{HCH}(13 \%)>\delta-\mathrm{HCH}(2.2 \%)>\varepsilon-\mathrm{HCH}$ $(1.1 \%)$ in soil. Because of the lower vapor pressure and more planar and symmetrical chemical structure, $\beta-\mathrm{HCH}$ was more stable and had a longer degradation half-time than $\alpha-\mathrm{HCH}$ and $\gamma-\mathrm{HCH}$, which consequently became the main isomer of $\mathrm{HCH}$ in the soil matrix. The moss samples collected in the present study normally grow on the soil matrix. A bivariate correlation analysis exhibited a significantly positive relationship $(p<0.05)$ of $\beta-\mathrm{HCH}$ between soil and mosses. Therefore, the potential influence of soil might be the reason for the higher percentage of $\beta-\mathrm{HCH}$ in the moss samples. The concentrations of hexachlorobenzene in the lichen, moss and soil samples were $1.1 \mathrm{ng} / \mathrm{g}$ $\mathrm{dm}, 0.42 \mathrm{ng} / \mathrm{g} \mathrm{dm}$, and $0.20 \mathrm{ng} / \mathrm{g} \mathrm{dm}$, respectively.

Compared with the above-mentioned OCPs, the other OCPs had very low concentrations and detection frequencies. Detailed information can be found in Tables S2, S3, and S4 in the Supplementary content.

As a whole, the concentrations of $\sum_{13} \mathrm{PBDE}, \sum_{18} \mathrm{PCB}$ and $\sum_{3} \mathrm{HBCD}$ were much lower than that of $\sum_{28} \mathrm{OCP}$. The respective average levels of $\sum_{13} \mathrm{PBDE}$ and $\sum_{18} \mathrm{PCB}$ were $0.16 \mathrm{ng} / \mathrm{g} \mathrm{dm}$ and $0.36 \mathrm{ng} / \mathrm{g} \mathrm{dm}$ in lichens, $0.028 \mathrm{ng} / \mathrm{g} \mathrm{dm}$ and $0.30 \mathrm{ng} / \mathrm{g} \mathrm{dm}$ in mosses, and $0.024 \mathrm{ng} / \mathrm{g} \mathrm{dm}$ and $0.057 \mathrm{ng} / \mathrm{g} \mathrm{dm}$ in soil. Lowly brominated congeners (tri-, tetra-, penta$\mathrm{BDE}$ ) accounted for $95 \%$ of the total concentration of $\sum_{13} \mathrm{PBDE}$ in soil. BDE-47 was the predominant isomer in soils and represented $53 \%$ of the $\sum_{13} \mathrm{PBDE}$, followed by BDE-99 with a concentration percentage of $27 \%$. The PBDE profile in both the lichen and moss matrices were evenly distributed and were predominated by middle-to-high-level brominated congeners (hexa-BDE $(37 \%)>$ hepta-BDE $(34 \%)>$ tetra-BDE $(17 \%)>$ penta-BDE $(10 \%)>\operatorname{tri}-\mathrm{BDE}(2.4 \%)$ in lichens; tetra-BDE $(29 \%)>$ hepta-BDE $(24 \%)>$ hexa-BDE $(18 \%)>$ penta-BDE $(16 \%)>$ tri$\operatorname{BDE}(13 \%)$ in mosses). In both the lichens and mosses, BDE-183 was the predominant congener and the corresponding concentration proportions were $30 \%$ and $24 \%$, respectively. For PCBs, the indicator PCBs (CB-28, 52, 101, 138, 153, and 180) were the predominant congeners in all three of the matrices, and accounted for $81 \%$ of the total concentration of $\sum_{18} \mathrm{PCB}$ in lichens, $95 \%$ in mosses, and $77 \%$ in soil. Therein, $\mathrm{CB}-28$ and $\mathrm{CB}-118$ were, respectively, the most predominate among the total 18 PCB congeners and 12 dioxin-like PCB congeners, which was consistent with Wang et al.'s observation (Wang et al., 2009). The PCB profile with a higher proportion of the lighter congeners, especially CB-28, in all three of the matrices suggested that the PCBs in the sampling region might come from other regions through long-range atmospheric transportation, because lighter PCBs have lower vapor pressure and higher ultraviolet degradation resistance than heavier PCB congeners.

HBCDs were only detected in the lichen samples with a detection frequency of $62 \%$, and the concentration of $\sum_{3} \mathrm{HBCD}$ was $0.14 \mathrm{ng} / \mathrm{g} \mathrm{dm}$. $\gamma$-HBCD dominated in the HBCD profile and presented $82 \%$ of $\sum{ }_{3} \mathrm{HBCD}$. The composition was consistent with commercial HBCDs mixtures, which have $75-89 \% \gamma$-HBCD, $10-13 \% \alpha$-HBCD and $1.0-12 \% \beta-H B C D$ (Peled et al., 1995).

Organic pollutants are always partitioned between the vapor state and inert lipophilic materials due to their hydrophobicity. The cytological mechanisms of pollutant adsorption by a biosorbent were proved to be correlated with the content of lipids, oligosaccharide and protein in the biosorbent (Cai et al., 2008). In this work, the TOC content of the soil samples was in a range of $0.80 \%$ to $21 \%$, with a mean value of $5.8 \%$. The respective dry-mass-based lipid contents of the lichen and moss were in a range of $5.9 \%$ to $30 \%$ with a mean value of $15 \%$ and in a range of $1.1 \%$ to $7.2 \%$ with a mean value of $3.6 \%$ (Table S1). The lipid content of lichen was approximately four times higher than that of moss. There was an interesting finding that the lipid content of moss had a significant positive correlation with the altitude $(p<0.05)$. From low altitude $(2736 \mathrm{~m})$ to high altitude $(4000 \mathrm{~m})$, the lipid content of moss increased approximately 3 fold. This might be due to the stronger synthesis of fat for their stronger frost resistances in the higher altitudes. Similar findings were also observed for pine needles, tree bark and xylem tissues (Hoch and Korner, 2003; Yang et al., 2013). To avoid the influence of altitudes on the concentration and lipid (or TOC) content, partial correlation analysis was carried out and indicated that there was no significant correlation between the soil TOC and the concentrations of each targeted compound, which was different from the observation of Yang's work where most of OCPs were significantly linearly correlated with the soil TOC (Yang et al., 2013). For lichens and mosses, the lipid content was found to be correlated with only a few SVOCs. The 2,4'-DDT, 4,4'-DDT, endosulfan I, endosulfan II, CB-52, BDE-71, BDE-100 and BDE-190 were linearly correlated with the lipid content in lichens. And 4,4'-DDT, endosulfan I, CB-118, as well as BDE-71 were linearly correlated with the lipid contents in mosses. 
To further determine the potential effect of the lipid content/TOC on the accumulation of SVOCs and the profile differences among the three types of matrices, the samples were simultaneously collected at the same sampling sites during the same sampling trip, called "comparison samples", and were used for data analysis (Table S1). Overall, the concentrations of the targeted compounds in the 19 comparison samples were analyzed. As shown in Fig. 1, the SVOCs in the soil samples had the lowest concentrations. The dry-weight-based concentrations of the $\sum_{28} \mathrm{OCP}$ in lichens were approximately 4 times higher than the ones in mosses, whereas the lipid-content-normalized concentrations of $\sum_{28} \mathrm{OCP}$ were close to that of the mosses. DDTs were the predominant components of OCPs and were significant correlated with the lipid content. The 4-fold higher lipid content of the lichens compared with the mosses could be the main reason for the markedly higher
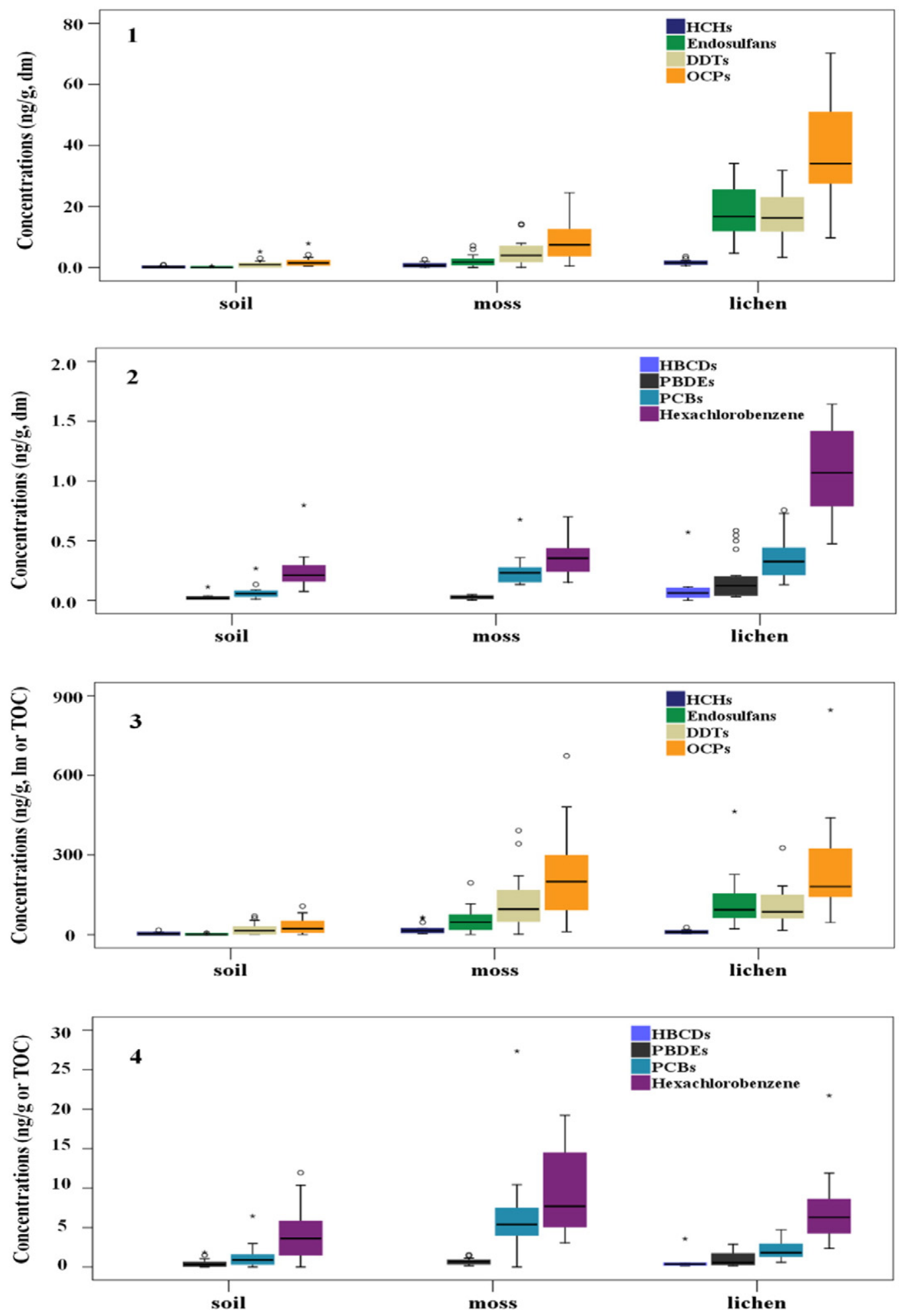

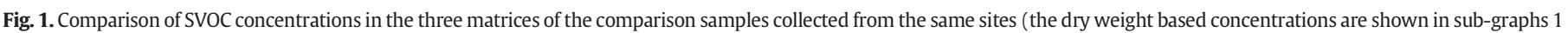
and 2, whereas the lipid content (or TOC) normalized concentrations are shown in sub-graphs 3 and 4). 
levels of $\sum_{28} \mathrm{OCP}$ in the lichens. Similar relationships were observed for $\sum_{6} \mathrm{DDT}, \sum_{2}$ endosulfan, hexachlorobenzene and $\sum_{13} \mathrm{PBDE}$. In contrast to the above-mentioned SVOCs, the lipid-content-normalized concentrations of $\sum_{5} \mathrm{HCH}$ and $\Sigma_{18} \mathrm{PCB}$ in the mosses were significantly higher than those in the lichens; however their dry-weight-based concentrations were still lower than those in the lichens. This was possibly due to the insignificant correlations between the lipid content and the concentration of $\sum_{5} \mathrm{HCH}$ and $\Sigma_{18} \mathrm{PCB}$. Furthermore, the detection frequencies of the target SVOCs in the lichens were normally higher than in the mosses, especially for the HBCDs, which were only found in the lichens. The SVOC detection frequencies in soil were not consistent with those in the mosses or lichens.

As a whole, the profiles of most SVOCs among the three matrices were similar, but a cluster analysis indicated that the patterns in mosses and lichens were closer (Fig. S2). Mosses and lichens exhibited more similarity in the profiles of DDTs, chlordanes and PBDEs than in soil, whereas the mosses and soil exhibited more similarity in the profiles of HCHs and endosulfans. A correlation analysis indicated that the concentrations of SOVCs in the lichens were not correlated with those in the soil or mosses, but high correlations existed between the mosses and soil (Fig. 2). The concentrations of PBDEs and PCBs in the mosses were significantly correlated with those in soil $(p<0.05)$, suggesting that the mosses might be influenced by soil in indicating the atmospheric occurrence of SVOCs.

\subsection{Potential source identification of SVOCs}

The ratio of (DDE + DDD)/DDT has been used to distinguish new $((\mathrm{DDE}+\mathrm{DDD}) / \mathrm{DDT}<1)$ or aged $((\mathrm{DDE}+\mathrm{DDD}) / \mathrm{DDT}>1)$ sources based on the fact that DDT can be gradually degraded and transformed into the stable metabolites DDE and DDD (Willett et al., 1998). The ratio values of $\left(4,4^{\prime}\right.$-DDD $+4,4^{\prime}$-DDE) $/ 4,4^{\prime}$-DDT and $\left(2,4^{\prime}\right.$-DDD $+2,4^{\prime}$-DDE)/ 2,4'-DDT were, respectively, 0.20 and 0.12 in lichens, 0.26 and 0.11 in mosses, and 1.1 and 0.18 in soil. Values lower than 1 indicate fresh inputs of DDTs on the southeastern Tibetan Plateau. Because the industrial DDT has been banned in China since 1983, the main sources were probably from the application of DDT-containing dicofol and the reemissions of industrial DDT residues from historic uses (Schrlau et al.,
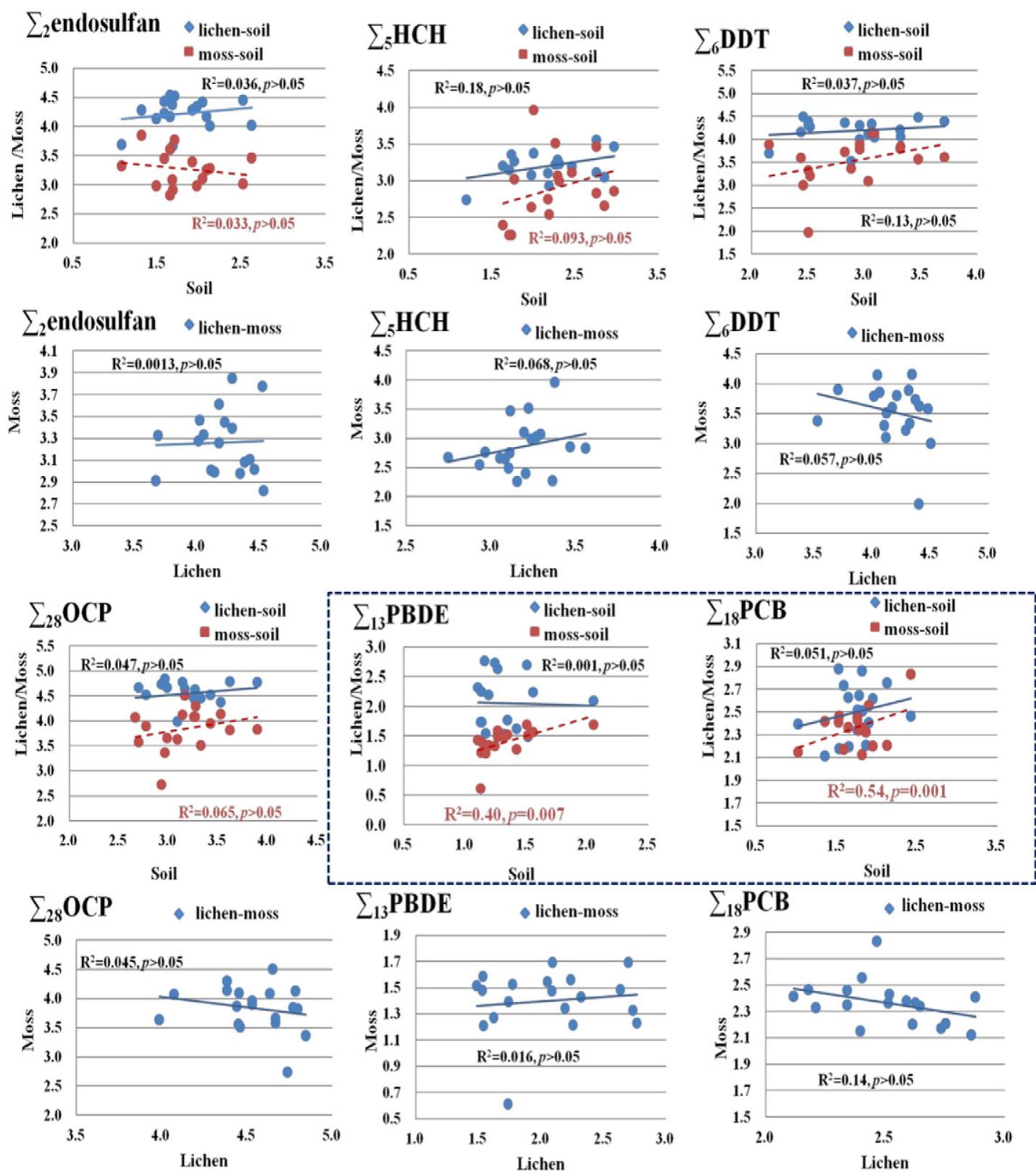

Fig. 2. SVOC concentration correlations among the three matrices. 
2011). The ratio of 2,4'-DDT/4,4'-DDT can be used to further distinguish the DDT sources because the ratios of 2,4'-DDT/4,4'-DDT in the industrial DDT and in the dicofol are different (0.2 and 7, respectively) (Qiu et al., 2005). The ratio of $2,4^{\prime}$-DDT $/ 4,4^{\prime}$-DDT in the lichens, mosses and soil were $0.67,0.61$, and 0.74 , respectively. These similar ratios among the three matrices commonly signified that the industrial DDT and dicofol might both contribute to the occurrence of DDTs on the Tibetan plateau. Because 2,4'-DDT was the predominant component of dicofol, the lower values of $\left(2,4^{\prime}\right.$-DDD $+2,4^{\prime}$-DDE $) / 2,4^{\prime}$-DDT than $\left(4,4^{\prime}-\right.$ DDD $+4,4^{\prime}$-DDE) $/ 4,4^{\prime}$-DDT in all three of the matrices implied that the input of dicofol was fresher than that of the industrial DDT. The distinctly higher value of $\left(4,4^{\prime}\right.$-DDD $+4,4^{\prime}$-DDE $) / 4,4^{\prime}$-DDT in the soil compared with the values in the lichens and mosses further indicated that the 4,4'-DDT degraded more rapidly in the soil.

Similarly, the ratios of $\alpha-\mathrm{HCH} / \gamma-\mathrm{HCH}$ were used to confirm the pollution sources of $\mathrm{HCHs}$, because the $\mathrm{HCHs}$ in the environment mainly come from the use of technical HCHs $(55-80 \% \alpha-\mathrm{HCH}, 5.0-14 \% \beta-$ $\mathrm{HCH}, 8.0-15 \% \gamma-\mathrm{HCH}$, and $2.0-16 \% \delta-\mathrm{HCH} ; \alpha-\mathrm{HCH} / \gamma-\mathrm{HCH}=3.0-7.0)$ and lindane (>99\% $\gamma-\mathrm{HCH} ; \alpha-\mathrm{HCH} / \gamma-\mathrm{HCH} \approx 0)$. The ratios of $\alpha-\mathrm{HCH} /$ $\gamma-\mathrm{HCH}$ in this study ranged from 1.0 to 2.6 (mean value of 1.7 ) in lichens, 0.0 to 3.5 (mean value of 1.3 ) in mosses, and 0.84 to 7.4 (mean value of 3.2 ) in soil, which suggested a combined influence from industrial $\mathrm{HCHs}$ and lindane on the southeastern Tibetan Plateau. The $\beta-\mathrm{HCH}$ was generally the predominant isomer in soil because of its high resistance to degradation. Therefore, the ratio of $\beta-\mathrm{HCH} /(\alpha-\mathrm{HCH}+\gamma-$ $\mathrm{HCH}$ ) could be used to indicate $\mathrm{HCH}$ aging in soil. If the value of $\beta$ $\mathrm{HCH} /(\alpha-\mathrm{HCH}+\gamma-\mathrm{HCH})$ was higher than 0.5 , no fresh input of $\mathrm{HCH}$ in the sampling region is assumed. Otherwise, fresh input of $\mathrm{HCH}$ occurred (Zhang et al., 2007). The ratio of $\beta-\mathrm{HCH} /(\alpha-\mathrm{HCH}+\gamma-\mathrm{HCH})$ in the soil of this research ranged from 0.09 to 0.48 , with a mean value of 0.20 , which indicated that there were fresh inputs of $\mathrm{HCHs}$ on the southeastern Tibetan Plateau.

The higher ratios of endosulfan I/endosulfan II in the three sample matrices compared with the one in the industrial mixture (2.0-2.3) (Estellano et al., 2008) suggested that there was no fresh input of commercial endosulfans in the sampling region based on the fact that endosulfan II gradually converts to endosulfan I over time (Schmidt et al., 2001). However, combing with the results of our previous work, the sampling region might still be under the influence of the longrange atmospheric transportation of endosulfans transported by the Indian monsoon in summer and the westerly in winter (Zhu et al., 2014).

Because there were no identified or reported local sources in the sampling region, the targeted SVOCs in the three types of matrices might be influenced by the atmospheric transport and secondary sources of residue re-emissions in this region (Sheng et al., 2013; Wang et al., 2010; Zhu et al., 2014). Our previous work (Zhu et al., 2014) indicated that the potential sources of SVOCs on the southeastern Tibetan Plateau probably come from southern Asia (mainly northeastern India) in the summer and southwestern Asia in the winter.

\subsection{Key factors governing the distributions of SVOCs on the southeastern Tibetan Plateau}

The sampling region in this study covers $920 \mathrm{~km}$ from the western sites to the eastern sites. The concentration levels of OCPs on the eastern sites were higher than those on the western sites, whereas the levels of PCBs and PBDEs, with the exception of PBDEs in lichens, were homogeneous throughout the sampling region (Fig. S3). The prevailing monsoons in the sampling region mainly originate from southwestern Asia and southern Asia, especially in the summer, and the eastern sites of this sampling region are located where monsoons enter to the southeastern Tibetan Plateau (Zhu et al., 2014); this geography results in higher levels of SVOCs in the eastern part than in the western part.

The altitudes of the sampling sites ranged from 2596 to $4144 \mathrm{~m}$ above sea levels. A partial correlation analysis indicated that 12 OCPs
( $\alpha$-HCH, $\gamma$-HCH, $\varepsilon-H C H, 4,4^{\prime}$-DDT, 2,4'-DDT, 4,4'-DDD, 2,4'-DDD, 4, 4' DDE, 2,4'-DDE, cis-heptachloroepoxide, endosulfan I, and endosulfan II) and 14 PCB congeners (CB-52, 101, 138, 153, 180, 126, 105, 114, $118,123,156,157,167$, and 189) in the lichen samples significantly linearly correlated with the altitudes of the sampling sites $(p<0.05)$, whereas the correlations between the altitudes and concentrations of SVOCs in the moss and soil samples were not significant (Fig. 3). The lipid-content-normalized concentrations of these SVOCs indicated similar trends by altitude, and the relationships are shown in Figs. S4 and S5. On the whole, the SVOC concentrations (based on the dry mass) in lichens increased approximately 10 -fold when the altitude increased from 2596 to $4144 \mathrm{~m}$, which indicated an obvious cold-trapping effect. However, for mosses, the concentration of SVOCs exhibited a decreasing trend by altitude, although it was not significant; for soil, the concentration trend remained constant with altitude. Several factors might be jointly responsible for the variable bioaccumulation behavior of SVOCs in the moss and lichen. One important factor might be the biological differences between the two species. Even though the exact nature of the biological differences is so far unknown, they may include the vitality state to uptake SVOCs, structural differences and availability of sorption sites, differences in the presence and composition of hydrophobic or amphoteric constituents, and so on. Kylin and Bouwman (2012) indicated that the hydration state was very important in mosses and lichens governing the uptake and revolatilization of airborne contaminants, such as HCHs. Mosses have three different water compartments: external capillary water, apoplast water in the cell walls, and symplast water within the cells (Proctor et al., 1998). The water compartmentalization of lichens is not as complex as that of mosses, but the hydration also affects their volume and surface area. Under the influence of the large moisture passage of the Yarlung Tsangpo Valley, which is close to the sampling region, the different vitality of mosses and lichens might be related to the different spatial distributions of these SVOCs with elevation. Secondly, Young and Banks (1998) indicated that the HCH adsorption of fungal biosorbent increased with decreasing temperature. Lichen is a complex life form that lives symbiotically with fungi and algae; thus, the decreasing temperature with increasing altitude might be related to the altitude-dependent gradient trend of SVOCs in lichens. Additionally, the host trees at the higher altitudes might ooze more hydrophobic oils to resist frost than those at lower altitudes, which may increase the lipid contents of lichens, further improving the uptake capacity of SVOCs for lichens in the higher altitude regions (Hoch and Korner, 2003; Yang et al., 2013). Conversely, a range of other studies also noted similar altitude-dependent gradient trend/cold-trapping effects for HCHs (Blais et al., 1998; Blais et al., 2003; Davidson et al., 2003; Shen et al., 2004), DDTs (Blais et al., 2003; Davidson et al., 2003; Shen et al., 2005), endosulfan II and PCBs (Blais et al., 1998) in the Canadian Rocky Mountains and the Alps. Similar altitude-dependent gradient trends in some SVOCs in the air in the same region were also observed in our previous results from a manufactured air sampler, XAD sampler (Zhu et al., 2014). Combined with these two studies, we further investigated the influence of physical-chemical properties on the altitudinal distribution of SVOCs on the Tibetan Plateau. The relevant values of octanol-water $\left(\log \mathrm{K}_{\mathrm{OW}}\right)$, octanol-air $\left(\log K_{\mathrm{OA}}\right)$, water-air $\left(\log K_{\mathrm{WA}}\right)$ partition coefficients are listed in Table S5. The frequency distribution histogram (Fig. 4) indicates that lichens had a similar distribution outline of SVOCs as the XAD-sampler as a whole, but that they accumulated a wider range of SVOCs than the XAD. The SVOCs with higher $\log K_{\mathrm{OA}}$ and $\log K_{\mathrm{WA}}$ are usually present in the particle phase of the atmosphere. Compared to the XAD-sampler, which mainly collects vapor-phase contaminants, vegetation like lichen could accumulate both vapor- and particle-phase contaminants from the air, which explains why a wider range of SVOCs may be detected in lichens. The SVOCs that had significantly positive correlations $(p<0.05)$ with the altitude in lichens and XAD mainly belonged to the ones with $\log K_{\mathrm{OA}}$ and $\log K_{\mathrm{WA}}$ values ranging from 8 to 11 and 2 to 4 , respectively. This was consistent with Schrlau et al. (2011) and the predications from a mountain 


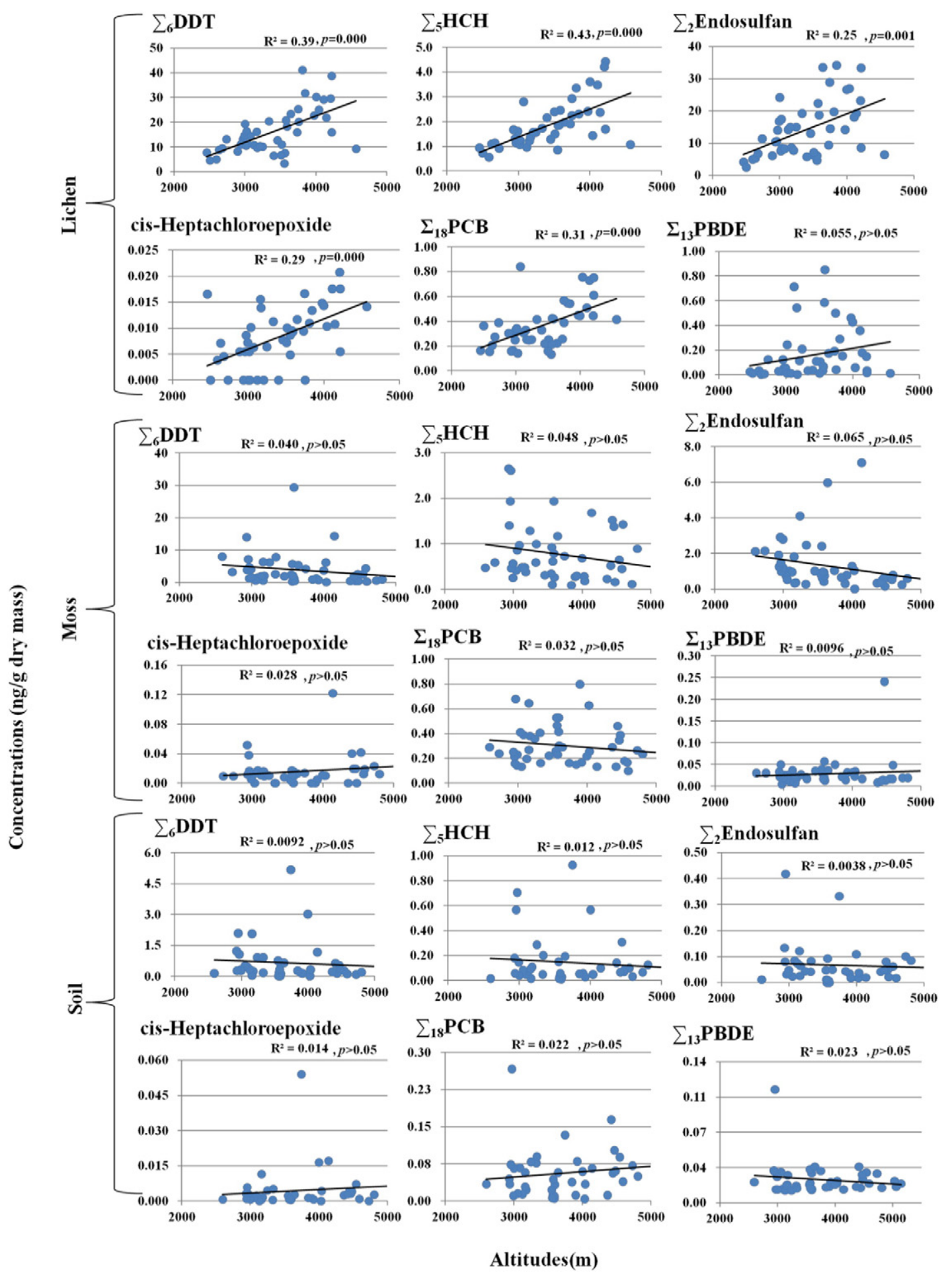

Fig. 3. Correlations between the dry-mass-based concentrations of SVOCs and the altitudes of all of the sampling sites.

contamination potential (MCP) model (Wania and Westgate, 2008). The MCP model (Fig. S6) predicted that HCHs, DDTs, endosulfan, heptachloroepoxide and indicator PCBs, of which the $\log K_{\mathrm{OA}}$ at $25{ }^{\circ} \mathrm{C}$ ranged from 8.5 to 11 and $\log K_{\mathrm{WA}}$ at $25{ }^{\circ} \mathrm{C}$ ranged from 3.5 to 5.5 , showed higher enrichment at higher altitudes with MCP values $>0.5$. On the other hand, hexachlorobenzene, PBDEs, HBCD and some other $\mathrm{PCB}$ isomers whose $\log K_{\mathrm{OA}}$ and $\log K_{\mathrm{WA}}$ values were outside of the range had MCP values $<0.5$. This predication was in strong agreement with our results (Figs. 3 and 4 ).

\section{Conclusions}

Pristine mountains are ideal settings for studying the transportation and behavior of SVOCs. The high detection level of SVOCs in the wideranging sampling region in this study proved that long-range transportation was responsible for the existence of SVOCs on the Tibetan Plateau. Furthermore, the significantly linear correlation between the lichen concentrations of SVOCs and altitude implies the existence of the coldtrapping effect. It is worthwhile to note that lichens (U. longissima) 

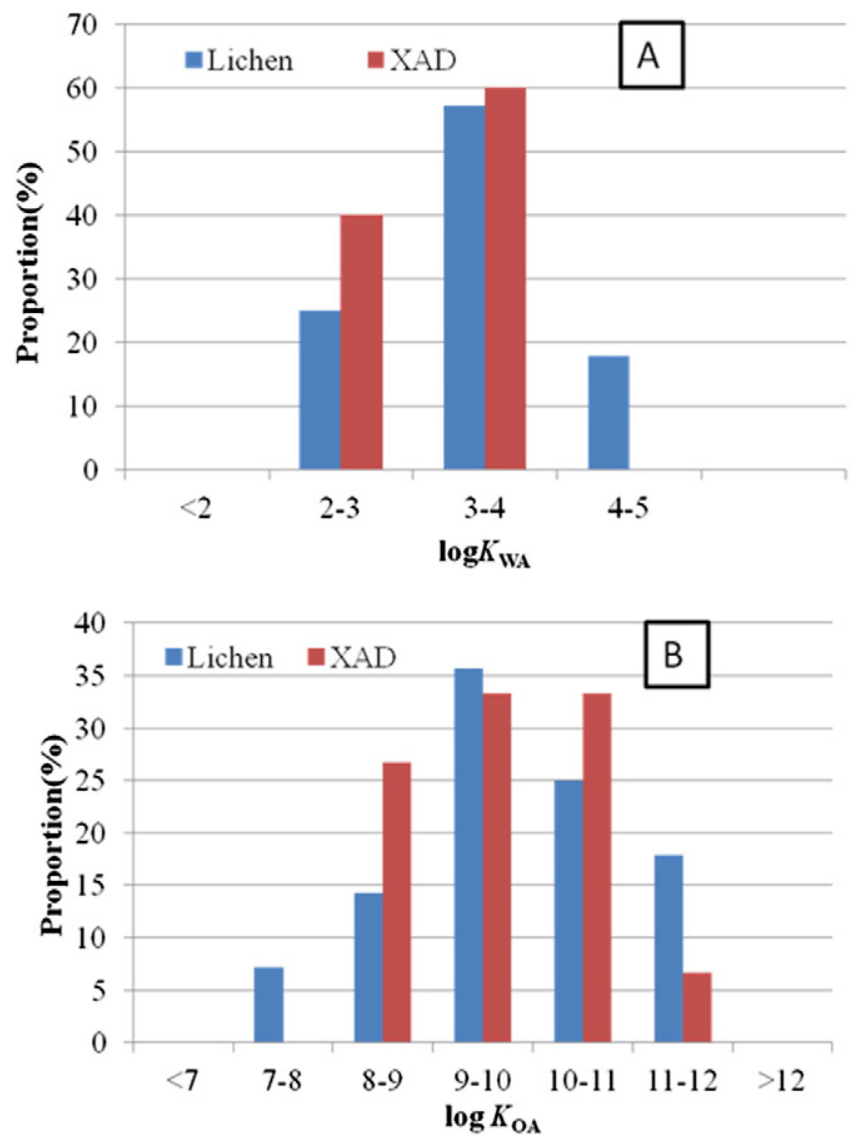

Fig. 4. Frequency distribution of the SVOCs with significant correlations between the concentration data and altitudes $(p<0.05)$ within a range of $\log K_{\mathrm{OA}}$ and $\log K_{\mathrm{AW}}$. For example, taking lichens in $5 \mathrm{~B}$ to illustrate Fig. 2 , in all of the SVOCs that had significant correlations with altitude $(p<0.05)$, those SVOCs with $\log K_{\mathrm{OA}}$ value in the range of 9 to 10 account for $36 \%$.

and mosses (Hypnaceae) share commonalities as air passive samplers to reveal the occurrence of SVOCs in the atmosphere, especially indicating the levels and profiles of SVOCs. However, there was some indication of differences between the two vegetation matrices in some situations, such as in the profile analysis of HCHs or in the altitudinal distribution of SVOCs. Under these conditions, the analytical results for the lichens (U. longissima) were close to the ones of manufactured air samplers-XADs, whereas the mosses (Hypnaceae) were similar to the soil. Lichens (U. longissima) tend to superior in revealing the SVOCs of air over mosses (Hypnaceae) and might be more suitable as a bioindicator of SVOC air contamination in remote areas, especially in high mountain regions.

\section{Acknowledgment}

This work was jointly supported by the Strategic Priority Research Program of the Chinese Academy of Sciences (XDB14010400), the Chinese Academy of Sciences (YSW2013B01), the National Natural Science Foundation (21177149, 21222702), and the National Basic Research Program of China (2014CB460612).

\section{Appendix A. Supplementary data}

Supplementary data to this article can be found online at http://dx. doi.org/10.1016/j.scitotenv.2015.03.024.

\section{References}

Augusto, S., Maguas, C., Matos, J., Pereira, M.J., Soares, A., Branquinho, C., 2009. Spatial modeling of PAHs in lichens for fingerprinting of multisource atmospheric pollution. Environ. Sci. Technol. 43, 7762-7769.

Bacci, E., Calamari, D., Gaggi, C., Fanelli, R., Focardi, S., Morosini, M., 1986. Chlorinated hydrocarbons in lichen and moss samples from the Antarctic Peninsula. Chemosphere $15,747-754$.

Blais, J.M., Schindler, D.W., Muir, D.C.G., Kimpe, L.E., Donald, D.B., Rosenberg, B., 1998. Accumulation of persistent organochlorine compounds in mountains of western Canada. Nature 395, 585-588.

Blais, J.M., Wilhelm, F., Kidd, K.A., Muir, D.C., Donald, D.B., Schindler, D.W., 2003. Concentrations of organochlorine pesticides and polychlorinated biphenyls in amphipods (Gammarus lacustris) along an elevation gradient in mountain lakes of western Canada. Environ. Toxicol. Chem. 22, 2605-2613.

Botaro, D., Torres, J.P., Malm, O., Rebelo, M.F., Henkelmann, B., Schramm, K.W., 2011. Organochlorine pesticides residues in feed and muscle of farmed Nile tilapia from Brazilian fish farms. Food Chem. Toxicol. 49, 2125-2130.

Buckley, E.H., 1982. Accumulation of airborne polychlorinated biphenyls in foliage. Science (New York, N.Y.) 216, 520-522.

Cabrerizo, A., Dachs, J., Barcelo, D., Jones, K.C., 2012. Influence of organic matter content and human activities on the occurrence of organic pollutants in antarctic soils, lichens, grass, and mosses. Environ. Sci. Technol. 46, 1396-1405.

Cai, J., Huang, Y., Li, X., 2008. Cytological mechanisms of pollutants adsorption by biosorbent. Chin. J. Ecol. 27, 1005-1011.

Cipro, C.V.Z., Yogui, G.T., Bustamante, P., Taniguchi, S., Sericano, J.L., Montone, R.C., 2011. Organic pollutants and their correlation with stable isotopes in vegetation from King George Island, Antarctica. Chemosphere 85, 393-398.

Daly, G.L., Lei, Y.D., Teixeira, C., Muir, D.C., Wania, F., 2007. Pesticides in western Canadian mountain air and soil. Environ. Sci. Technol. 41, 6020-6025.

Davidson, D.A., Wilkinson, A.C., Blais, J.M., Kimpe, L.E., McDonald, K.M., Schindler, D.W., 2003. Orographic cold-trapping of persistent organic pollutants by vegetation in mountains of western Canada. Environ. Sci. Technol. 37, 209-215.

Eriksson, G., Jensen, S., Kylin, H., Strachan, W., 1989. The pine needle as a monitor of atmospheric-pollution. Nature 341, 42-44.

Estellano, V.H., Pozo, K., Harner, T., Franken, M., Zaballa, M., 2008. Altitudinal and seasonal variations of persistent organic pollutants in the Bolivian Andes Mountains. Environ. Sci. Technol. 42, 2528-2534.

Feng, J.Y., Wang, Y.W., Ruan, T., Qu, G.B., Jiang, G.B., 2010. Simultaneous determination of hexabromocyclododecanes and tris (2,3-dibromopropyl) isocyanurate using LCAPCI-MS/MS. Talanta 82, 1929-1934.

Harner, T., Shoeib, M., Diamond, M., Stern, G., Rosenberg, B., 2004. Using passive air samplers to assess urban-rural trends for persistent organic pollutants. 1. Polychlorinated biphenyls and organochlorine pesticides. Environ. Sci. Technol. 38, 4474-4483.

Hoch, G., Korner, C., 2003. The carbon charging of pines at the climatic treeline: a global comparison. Oecologia 135, 10-21.

Kansri, B., Thomas, H., Nash, I., 1990. Seasonal variation of elemental status in the lichen Ramalina menziesii tayl. From two sites in southern California: Evidence for dry deposition accumulation. Environ. Exp. Bot. 30, 415-428.

Kylin, H., Bouwman, H., 2012. Hydration state of the moss Hylocomium splendens and the Lichen Cladina stellaris governs uptake and revolatilization of airborne alpha- and gamma-hexachlorocyclohexane. Environ. Sci. Technol. 46, 10982-10989.

Liu, W., Chen, D., Liu, X., Zheng, X., Yang, W., Westgate, J.N., Wania, F., 2010. Transport of semivolatile organic compounds to the Tibetan plateau: spatial and temporal variation in air concentrations in mountainous Western Sichuan, China. Environ. Sci. Technol. 44, 1559-1565.

Madl, P., Heinzelmann, E., Hofmann, W., Turk, R., 2010. Motorway exhaust aerosols and their effects on epiphytic lichen populations. Gefahrstoffe - Reinhalt. Luft 70, 147-153.

Negoita, T.G., Covaci, A., Gheorghe, A., Schepens, P., 2003. Distribution of polychlorinated biphenyls (PCBs) and organochlorine pesticides in soils from the East Antarctic coast. J. Environ. Monit. 5, 281-286.

Ockenden, W.A., Steinnes, E., Parker, C., Jones, K.C., 1998. Observations on persistent organic pollutants in plants: implications for their use as passive air samplers and for POP cycling. Environ. Sci. Technol. 32, 2721-2726.

Park, H., Lee, S.H., Kim, M., KIM, J.H., Lim, H.S., 2010. Polychlorinated biphenyl congeners in soils and lichens from King George Island, South Shetland Islands, Antarctica. Antarct. Sci. 22, 31-38.

Peled, M., Scharia, R., Sondack, D., 1995. Thermal rearrangement of hexabromocyclododecane (HBCD). Ind. Chem. Libr. 7, 92-99.

Proctor, M.C.F., Nagy, Z., Csintalan, Z., Takacs, Z., 1998. Water-content components in bryophytes: analysis of pressure-volume relationships. J. Exp. Bot. 49, 1845-1854.

Qiu, X.H., Zhu, T., Yao, B., Hu, J.X., Hu, S.W., 2005. Contribution of dicofol to the current DDT pollution in China. Environ. Sci. Technol. 39, 4385-4390.

Salamova, A., Hites, R.A., 2010. Evaluation of tree bark as a passive atmospheric sampler for flame retardants, PCBs, and organochlorine pesticides. Environ. Sci. Technol. 44, 6196-6201.

Schmidt, W.F., Bilboulian, S., Rice, C.P., Fettinger, J.C., McConnell, L.L., Hapeman, C.J., 2001. Thermodynamic, spectroscopic, and computational evidence for the irreversible conversion of beta- to alpha-endosulfan. J. Agric. Food Chem. 49, 5372-5376.

Schrlau, J.E., Geiser, L., Hageman, K.J., Landers, D.H., Simonich, S.M., 2011. Comparison of lichen, conifer needles, passive air sampling devices, and snowpack as passive sampling media to measure semi-volatile organic compounds in remote atmospheres. Environ. Sci. Technol. 45, 10354-10361.

Shen, L., Wania, F., Lei, Y.D., Teixeira, C., Muir, D.C., Bidleman, T.F., 2004. Hexachlorocyclohexanes in the North American atmosphere. Environ. Sci. Technol. 38, 965-975. 
Shen, L., Wania, F., Lei, Y.D., Teixeira, C., Muir, D.C., Bidleman, T.F., 2005. Atmospheric distribution and long-range transport behavior of organochlorine pesticides in North America. Environ. Sci. Technol. 39, 409-420.

Sheng, J., Wang, X., Gong, P., Joswiak, D.R., Tian, L., Yao, T., Jones, K.C., 2013. Monsoondriven transport of organochlorine pesticides and polychlorinated biphenyls to the Tibetan Plateau: three year atmospheric monitoring study. Environ. Sci. Technol. 47, 3199-3208.

Simonich, S.L., Hites, R.A., 1995. Organic pollutant accumulation in vegetation. Environ. Sci. Technol. 29, 2905-2914.

Tarcau, D., Cucu-Man, S., Boruvkova, J., Klanova, J., Covaci, A., 2013. Organochlorine pesticides in soil, moss and tree-bark from North-Eastern Romania. Sci. Total Environ. 456-457, 317-324.

Turgut, C., Atatanir, L., Mazmanci, B., Mazmanci, M.A., Henkelmann, B., Schramm, K.W., 2012. The occurrence and environmental effect of persistent organic pollutants (POPs) in Taurus Mountains soils. Environ. Sci. Pollut. Res. Int. 19, 325-334.

Wang, P., Zhang, Q., Wang, Y., Wang, T., Li, X., Li, Y., Ding, L., Jiang, G., 2009. Altitude dependence of polychlorinated biphenyls (PCBs) and polybrominated diphenyl ethers (PBDEs) in surface soil from Tibetan Plateau, China. Chemosphere 76, 1498-1504.

Wang, X.P., Gong, P., Yao, T.D., Jones, K.C., 2010. Passive air sampling of organochlorine pesticides, polychlorinated biphenyls, and polybrominated diphenyl ethers across the Tibetan Plateau. Environ. Sci. Technol. 44, 2988-2993.

Wang, P., Zhang, Q.H., Wang, T., Chen, W.H., Ren, D.W., Li, Y.M., Jiang, G.B., 2012. PCBs and PBDEs in environmental samples from King George Island and Ardley Island, Antarctica. Rsc Adv. 2, 1350-1355.

Wania, F., Westgate, J.N., 2008. On the mechanism of mountain cold-trapping of organic chemicals. Environ. Sci. Technol. 42, 9092-9098.

Willett, K.L., Ulrich, E.M., Hites, R.A., 1998. Differential toxicity and environmental fates of hexachlorocyclohexane isomers. Environ. Sci. Technol. 32, 2197-2207.
Yang, R., Yao, T., Xu, B., Jiang, G., Zheng, X., 2008. Distribution of organochlorine pesticides (OCPs) in conifer needles in the southeast Tibetan Plateau. Environ. Pollut. 153 92-100.

Yang, R., Zhang, S., Li, A., Jiang, G., Jing, C., 2013. Altitudinal and spatial signature of persistent organic pollutants in soil, lichen, conifer needles, and bark of the southeast Tibetan Plateau: implications for sources and environmental cycling. Environ. Sci. Technol. 47, 12736-12743.

Yogui, G.T., Sericano, J.L., 2008. Polybrominated diphenyl ether flame retardants in lichen and mosses from King George Island, maritime Antarctica. Chemosphere 73, 1589-1593.

Yogui, G.T., Sericano, J.L., Montone, R.C., 2011. Accumulation of semivolatile organic compounds in Antarctic vegetation: a case study of polybrominated diphenyl ethers. Sci. Total Environ. 409, 3902-3908.

Young, E., Banks, C.J., 1998. The removal of lindane from aqueous solution using a fungal biosorbent: the influence of $\mathrm{pH}$, temperature, biomass concentration and culture age. Environ. Technol. 19, 619-625.

Zhang, H.Y., Gao, R.T., Huang, Y.F., Jia, X.H., Jiang, S.R., 2007. Spatial variability of organochlorine pesticides (DDTs and $\mathrm{HCHs}$ ) in surface soils from the alluvial region of Beijing, China. J. Environ. Sci. (China) 19, 194-199.

Zhu, N., Li, A., Wang, T., Wang, P., Qu, G., Ruan, T., Fu, J., Yuan, B., Zeng, L., Wang, Y., Jiang G., 2012. Tris(2,3-dibromopropyl) isocyanurate, hexabromocyclododecanes, and polybrominated diphenyl ethers in mollusks from Chinese Bohai Sea. Environ. Sci. Technol. 46, 7174-7181.

Zhu, N., Schramm, K.W., Wang, T., Henkelmann, B., Zheng, X., Fu, J., Gao, Y., Wang, Y., Jiang G., 2014. Environmental fate and behavior of persistent organic pollutants in Shergyla Mountain, southeast of the Tibetan Plateau of China. Environ. Pollut. 191, 166-174. 